\title{
The use of concentrated heat after insect bites/ stings as an alternative to reduce swelling, pain, and pruritus: an open cohort-study at German beaches and bathing-lakes
}

This article was published in the following Dove Press journal:

Clinical, Cosmetic and Investigational Dermatology

I4 December 20II

Number of times this article has been viewed

\author{
Christian Müller ${ }^{1, *}$ \\ Beatrice Großjohann 1,* \\ Lutz Fischer ${ }^{2, *}$ \\ 'Department of Medical Science and \\ Operations, RIEMSER Arzneimittel \\ AG, An der Wiek 7, 17489 Greifswald, \\ ${ }^{2}$ Department of Anesthesiology \\ and Intensive Medicine, University \\ Greifswald, Friedrich-Loeffler-Straße \\ 23b, I 7493 Greifswald, Germany \\ *These authors contributed equally \\ to this work
}

\begin{abstract}
Background: Swelling, pain, and pruritus are the most relevant symptoms after insect bites/ stings. Glucocorticoids and antihistamines are well established in insect sting treatment. Bite Away ${ }^{\circledR}$ is a CE-certified medical device of class 2A (noninvasive device intended for administration to the body, which exchanges energy with the patient in a therapeutic manner) to reduce swelling, pruritus, and pain after insect bites/stings via non-invasive administration of concentrated heat to the skin. We therefore performed a prospective, non-interventional, singlearm cohort study with 146 volunteers using the visual analog scale (VAS) for insect bites/stings to study the reduction of swelling, pruritus, and pain. Demographic data, time from insect sting to treatment, number and duration of administrations of concentrated heat, relevant symptoms, and the development of a VAS score of swelling, pruritus, and pain on baseline, after 2, 5, and 10 minutes after administration, were registered.
\end{abstract}

Results: In total 146 subjects with a mean age of 29.4 \pm 20.7 years (range 2-81) were enrolled in the study. Ninety-three (63.7\%) of the subjects were stung by wasps, $33(22.6 \%)$ of the subjects were bitten by mosquitoes, and eight suffered bee stings (5.3\%). VAS score swelling decreased with statistical significance after the use of Bite Away ${ }^{\circledR}$ from 4 before treatment to 2 and 1 after $2-5$ and 10 minutes, respectively. VAS pain score was 6 before treatment, 2 after 2 minutes, 1 after 5 minutes, and 0 after 10 minutes (median). VAS pruritus score was only available for $52(35.2 \%)$ of the patients. The score decreased from 5 before treatment, to 2 after 2 minutes, and 0 after 5 and 10 minutes.

Conclusions: Locally administrated concentrated heat leads to fast amelioration of symptoms. Usually an absence of symptoms is noticeable 10 minutes after administration. Pain reduction is the dominant effect. Compared with alternatives of pruritus and pain treatment after insect bites/stings, Bite Away ${ }^{\circledR}$ seems to be the fastest treatment option available.

Keywords: insect bites/stings, swelling, pain, pruritus, concentrated heat, VAS

\section{Introduction}

Swelling, pruritus, and pain are the most relevant symptoms after insect bites/stings. ${ }^{1}$ Insects inject a pruritic and/or pain-inducing substance through the epidermis into the dermis with their saliva. Allergic reactions are mediated by immunoglobulins that target specific antigens in hymenopteran venoms. ${ }^{2}$ A cascade of activation of histamine receptors, followed by neurogene inflammation and edema, erythema, and itching is induced. ${ }^{3,4}$ The prevalence of stinging insect hypersensitivity reactions ranges from $0.4 \%$ to $3.3 \%{ }^{5-7}$ and causes approximately 40 to 100 deaths in the US each year. ${ }^{8,9}$ Insect stings are regularly treated with removal of the stingers, cooling, and over-the-counter
Correspondence: Christian Müller Department of Medical Science and Operations, RIEMSER Arzneimittel AG, An der Wiek 7, 17493 Greifswald, Germany

Email mueller@riemser.de 
medications. Most common are topical glucocorticoids, and topical or systemic antihistamines. Only in cases of acute anaphylaxis is epinephrine an essential drug for emergency therapy. ${ }^{8,10,11}$ Several domestic remedies are used such as onions, lemons, saliva, vinegar, or tea tree oil with no evidence for effectiveness in insect sting therapy.

Bite Away ${ }^{\circledR}$ (RIEMSER Arzneimittel AG, Greifswald, Germany) is a CE-certified medical device of class $2 \mathrm{~A}$ (noninvasive device intended for administration to the body, which exchanges energy with the patient in a therapeutic manner) for noninvasive administration to the skin to reduce swelling, pruritus, and pain after insect bites/stings. Its microchip-controlled time-heat-constant guarantees a maximum temperature of $51^{\circ} \mathrm{C}$ on a $38.5-\mathrm{mm}^{2}$ gold-covered plate for either 3 or 6 seconds. Patients individually choose the 3 -second button (this modus is recommended for anxious people or children) or the 6-second button (for anybody else, who can accept the duration of treatment), which activates the device.

So far, the effects of concentrated heat on skin after insect bites/stings have not been evaluated in any single study. We therefore performed a prospective, non-interventional, single-arm cohort study with 146 volunteers to study the reduction of the visual analog scale (VAS) score of swelling, pain, and pruritus after insect bites/stings at German beaches and bathing lakes.

\section{Methods}

Bite Away ${ }^{\circledR}$ was used in collaboration with the German Life Saving Federation and the German Red Cross, section Baywatch (Wasserwacht), near bathing lakes and beaches in north east Germany. First aiders received a detailed briefing on insect bites/stings management with Bite Away ${ }^{\circledR}$, handling of patient recruitment, and documentation within the questionnaire by Lutz Fischer, MD. The observation period was from March to October 2009.

\section{Patient selection}

Lifeguards on their lifeguard towers or headquarters were the first contact persons to treat insect bites/stings. Because Bite Away ${ }^{\circledR}$ was used in routine treatment at all study sites, every case of an insect sting was enrolled in this study after provision of a brief explanation to the patient, and the patient giving informed consent. There was no selection of subjects with a known hypersensitivity to insect bites/stings. A questionnaire created in advance was filled in by the first aider. Demographic data, time from insect sting to treatment, number and duration of administrations, relevant symptoms, and the development of VAS for swelling, pruritus, and pain on baseline, 2, 5, and

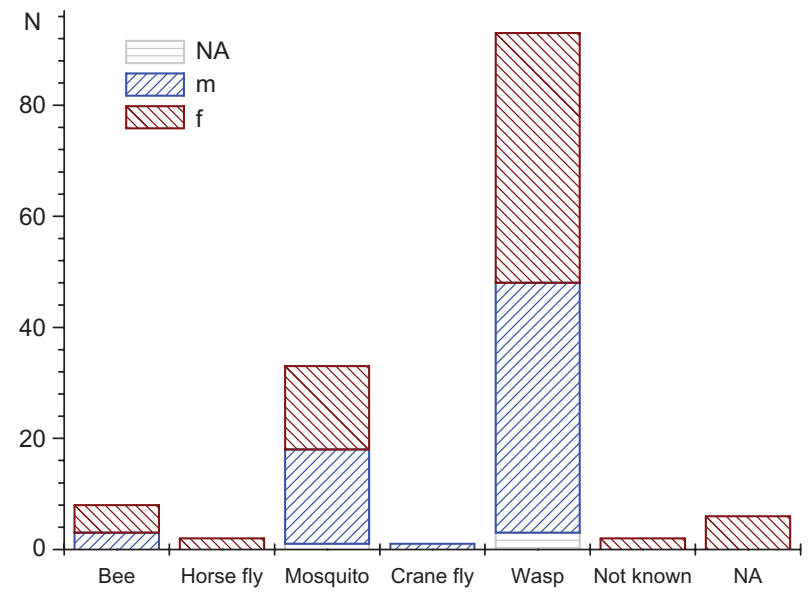

Figure I Frequency and type of insect bite/sting presented for subgroups of male (m) and female (f).

Abbreviation: NA, data not available.

10 minutes after administration, were registered. Patients voted their individual swelling, pruritus, and pain perception on a scale of 0 (none) to 10 (worst imaginable perception). In general, children selected the 3 -second modus, and adults selected the 6-second modus. Depending on the area of the bites/stings and the pain perception of the patient, both first aider and patient made the decision on the number of treatments.

\section{Data management}

An Excel spreadsheet was used for single data entry. The structure of the database was adapted from the questionnaire.

Table I Symptoms of insect bites/stings and mode of administration of Bite Away ${ }^{\circledR}$

\begin{tabular}{lll}
\hline & N & Frequency (\%) \\
\hline Symptoms & 108 & 74 \\
Swelling & 85 & 58.2 \\
Pain & 52 & 35.6 \\
Pruritus & 2 & 1.4 \\
Dyspnea & & \\
Duration of administration & 62 & 42.5 \\
3 seconds & 75 & 51.4 \\
6 seconds & & \\
Number of administrations & 66 & 45.2 \\
Once & 36 & 24.7 \\
Twice & 13 & 8.9 \\
Three times & 6 & 4.1 \\
Four times & 5 & 3.4 \\
Five times & 20 & 13.7 \\
NA & \\
Time of administration after insect bite & \\
Within 5 minutes & 73 & 50 \\
Within I5 minutes & 106 & 72.6 \\
More than I hour & 19 & 13 \\
NA & 15 & 10.3 \\
\hline Abbreviation: NA, & &
\end{tabular}

Abbreviation: NA, data not available. 
All analyses were performed using SAS software (v 9.2; SAS Institute Inc, Cary, NC). Data are expressed as mean, standard deviation, median (with interquartile range [IQR]), minimum and maximum. Comparisons of VAS scores were evaluated using the Wilcoxon test $(P<0.05$ was considered statistically significant). Statistical tests only have descriptive character. For missing data the last observation carried forward method was used.

\section{Results}

In total, 146 subjects (67 male, 72 female: for five subjects sex was not specified) were enrolled in the study. The mean age of the patients was $29.4 \pm 20.7$ years (range $2-81$ years). Wasp stings were observed in 93 (63.7\%) subjects, mosquito stings in $33(22.6 \%)$ subjects, and bee stings in $8(5.3 \%)$ subjects (Figure 1). Among all the patients, 108 (74\%) had swelling, $85(58.2 \%)$ had pain, $84(57.5 \%)$ had erythema (reddening of the skin), $52(35.6 \%)$ had pruritus, and two $(1.4 \%)$ had dyspnea. The frequency of symptoms as well as the number and duration of Bite Away ${ }^{\circledR}$ administrations are all listed in Table 1. In general, patients contacted the lifeguards immediately ( $72.6 \%$ of patients within 15 minutes). Although swelling was registered for 108 patients, only 95 data sets for a VAS score swelling were available. VAS score swelling decreased with statistical significance after the use of Bite Away $^{\circledR}$ from 4 before treatment to 2 and 1 after 2-5 and 10 minutes, respectively (Figure 2A). VAS pain score was 6 before treatment, 2 after 2 minutes, 1 after 5 minutes,
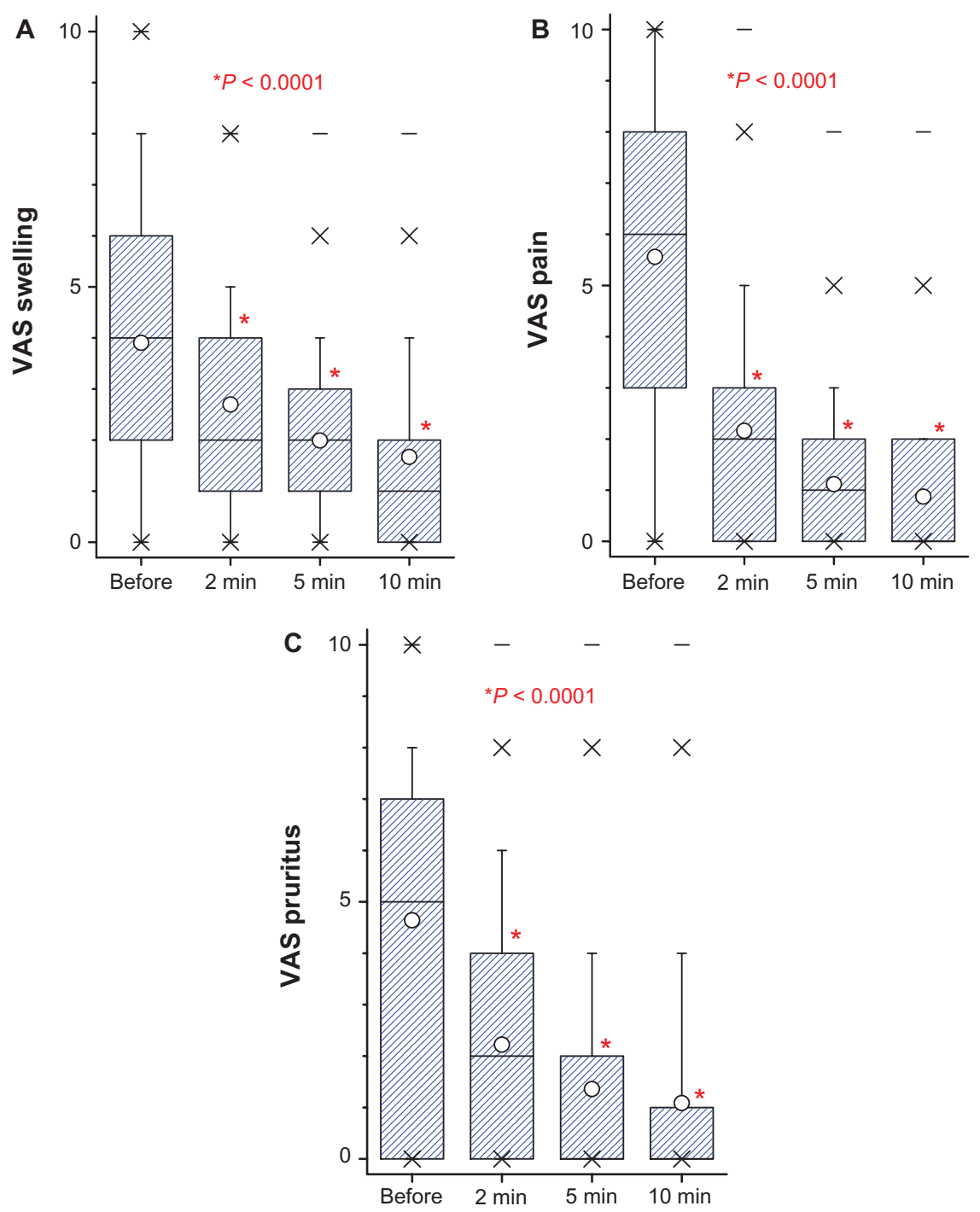

Figure 2 Box-plot of VAS values (on a scale of 10 = maximum severity) of swelling (A), pain (B) and pruritus (C). Results are given for development of symptoms after 2 , 5 , and 10 minutes after administration of Bite Away ${ }^{\circledR}$ compared with situation before treatment.

Note: Significantly different $P$ values of Wilcoxon test for comparison between time-points are presented.

Abbreviation: VAS, visual analog scale. 
and 0 after 10 minutes (Figure 2B). By observing the pain perception of the subgroup of patients with wasp bites, an $86 \%$ reduction of VAS was visible (VAS $7.32 \pm 2.45$ before treatment to VAS $1.03 \pm 1.21 ; P<0.0001)$. Because of the high rate of wasp stings, VAS pruritus score was only available for $52(35.2 \%)$ patients. Stratifying the cohort by age, there was a comparable reduction of VAS score swelling over time for children (under 6 years), for adolescents (from 6 to 18 years), and for adults (above 18 years) (Figure $3 \mathrm{~A}$ and B). .

Similarly, a statistical significant decrease of the VAS pruritus score was visible from 5 before treatment, to 2 after 2 minutes, and 0 after 5 and 10 minutes (Figure 2C). The decrease of VAS pruritus of the two subgroups' patients with wasps or mosquito bites is comparable. Immediately after administration of Bite Away ${ }^{\circledR}$, there was a significant decrease of pruritus whether the patient was stung/bitten by a wasp or a mosquito (Figure 4).
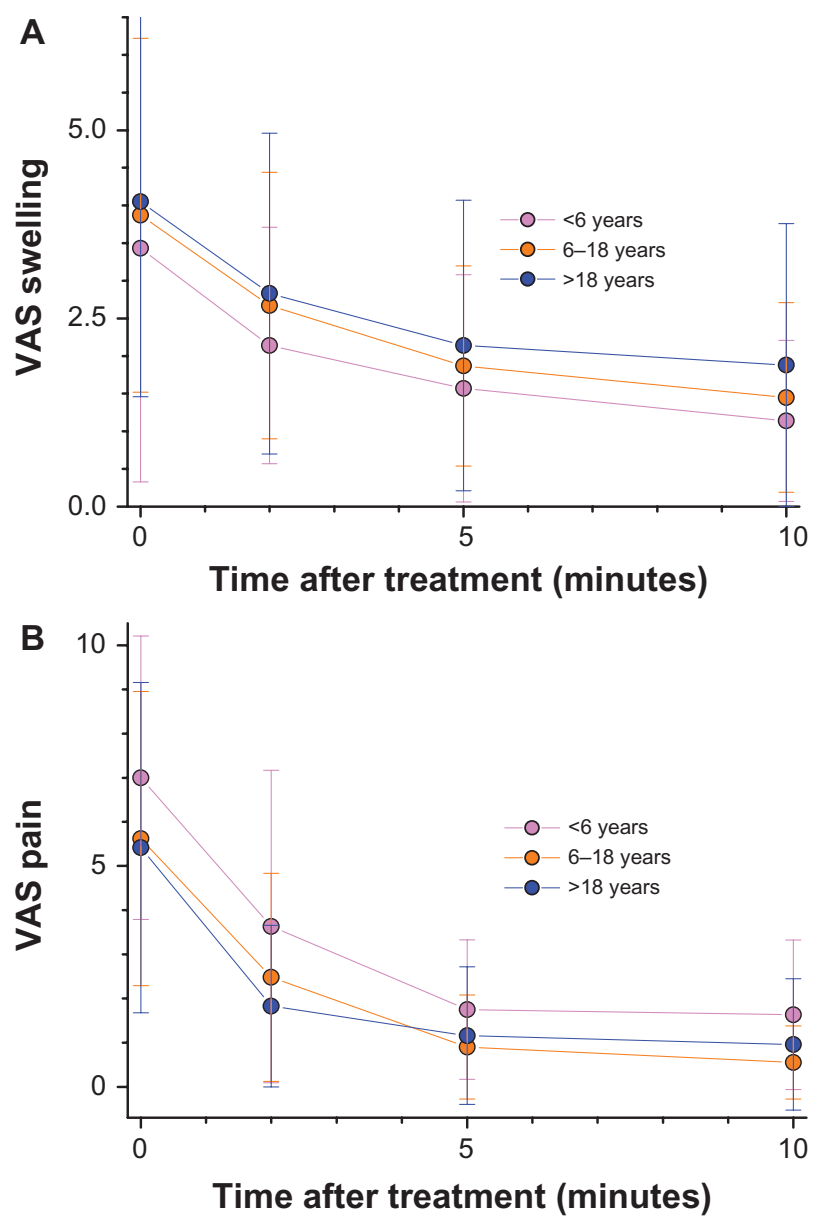

Figure 3 Reduction of swelling (A) and pain (B) is presented as VAS (on a scale of $10=$ maximum severity) for each time-point of measurement stratified by age of patients.

Note: Wilcoxon tests show no statistical differences between subgroups $(P>0.05)$ for $0,2,5$, and 10 minutes.

Abbreviation: VAS, visual analog scale.

\section{Discussion}

In this realistic field study, we found a rapid effect after Bite Away ${ }^{\circledR}$ administration on VAS score for swelling, pain, and pruritus after insect bites/stings. Locally administered, concentrated heat, which was recognized by the patients as a very short and targeted induction of almost painful high temperature on the skin, led to a fast improvement of symptoms. The symptoms usually faded away after 10 minutes. Pain reduction, especially for patients with wasp stings, was the dominant effect. In the context of a noninterventional trial in 2009, an alternative topical treatment with hydrocortisone also showed a reduction of pain, itch, erythema, and swelling after insect stings, but the symptom scores decreased slowly over a period of 7 days. ${ }^{12}$ In an experimental setting, 12 atopic dermatitis patients received a focal histamine stimulus $(20 \mathrm{mC})$ given by iontophoresis, which was treated with anesthetics (lidocaine, prilocaine, xylocaine) and antihistamines (dimetindene maleate). None of the antihistaminic and anesthetic agents reduced the pruritus intensity significantly, when applied for 15 minutes. ${ }^{13}$ In contrast, a placebo-controlled, cross-over study in 27 mosquito-bite-sensitive subjects showed that prophylactically given cetirizine $10 \mathrm{mg}$ and ebastine $10 \mathrm{mg}$ daily had a significant effect on wheals and pruritus caused by Aedes aegypti laboratory mosquitoes. ${ }^{14}$ When cetirizine $10 \mathrm{mg}$ was given prophylactically alone, only VAS scores of pruritus differed significantly from the placebo group after 15 and 60 minutes but not after 12 and 24 hours, in a field study in southern Finland, with Aedis communis mosquitos. ${ }^{15}$ An explanation of the mechanism of action for the effectiveness of concentrated heat in this study can be found in the activation and suppression of receptors. A rapid temperature increase to a maximum of $51^{\circ} \mathrm{C}$ leads to an activation of transient receptor potential cation channel subfamily $\mathrm{V}$ member 1 (TRPV1) via C-and A $\delta$-fibers. ${ }^{16}$ Midge saliva leads to an activation effect comparable to the stimulation of the proteinase-activated receptor-2 (PAR-2). ${ }^{17}$ PAR-2 are localized on human skin mast cells. PAR2 activation leads to an increase of $\mathrm{Ca}^{2+}$ ions from intracellular calcium stores and subsequent histamine release. ${ }^{18}$ Through the activation of TRPV1 by concentrated heat, PAR-2 carrying C-fibers may be influenced, suppressing pruritus. Further clinical studies showed that itch intensity ratings were significantly reduced during repeated noxious heat. ${ }^{19,20}$

Neither the concentrated heat during treatment, nor the number of administrations showed any influence on pain perception after 2, 5, and 10 minutes. This could be seen even in the stratum of children less than 6 years, who show a much 
A

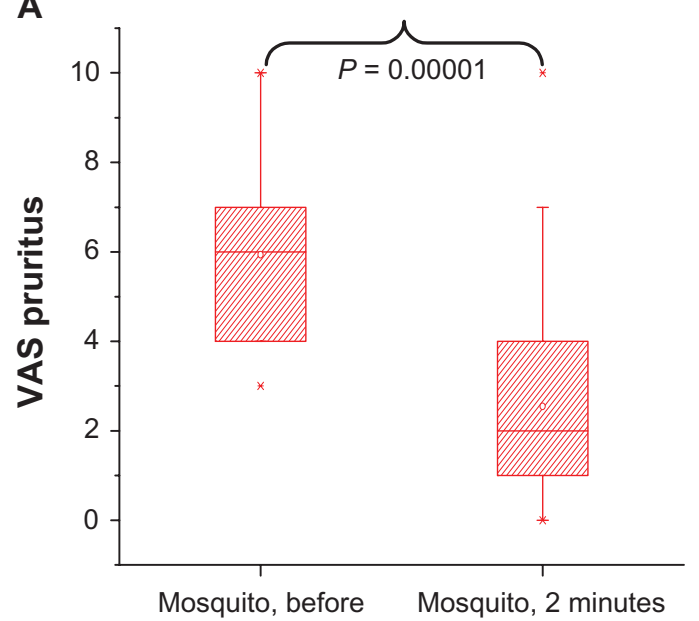

B

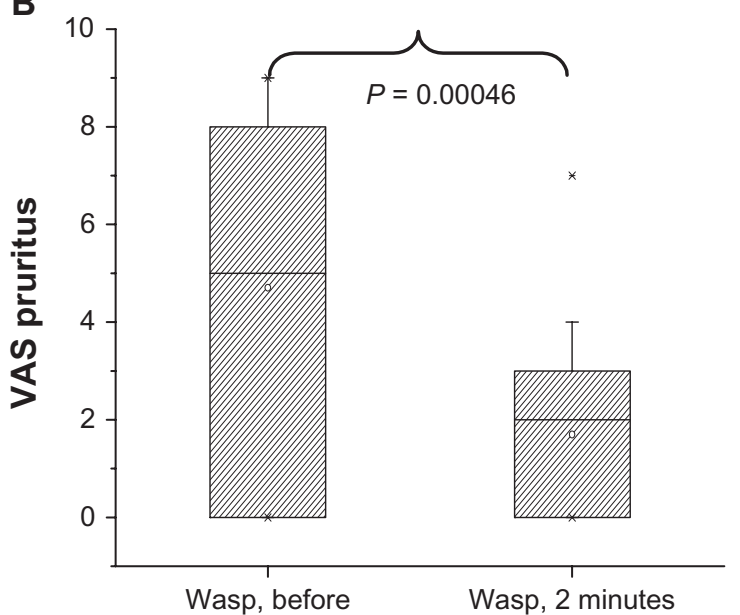

Figure 4 The reduction of VAS pruritus (on a scale of $10=$ maximum severity) is presented as box-plot stratified for insect type. A highly significant reduction of pruritus is visible for mosquitos (A) and wasps (B) before treatment, to 2 minutes after treatment with Bite Away ${ }^{\circledR}$.

Note: $P$ values of the Wilcoxon test for comparison between time-points are presented, (wasp $N=20$; mosquito $N=32$ ).

more pronounced cutaneous pain perception. Interestingly, only a few patients needed additional medical treatment. Due to the study design, it could not be established for sure whether the two female patients suffering from dyspnea had an anaphylactic reaction. Nevertheless, the effectiveness of Bite Away ${ }^{\circledR}$ in treating severe insect sting anaphylaxis is known to the authors from the emergency medical services. Controlled studies of the efficacy of the treatment of severe insect sting anaphylaxis and the mode of action of Bite Away ${ }^{\circledR}$ are still necessary.

\section{Conclusions}

Bite Away ${ }^{\circledR}$ reduced VAS scores significantly for swelling, pruritus, and pain when used after insect bites/stings in this open cohort-study. Compared with alternatives of pruritus and pain treatment after insect bites/stings, Bite Away ${ }^{\circledR}$ seems to be the fastest treatment option already available.

\section{Acknowledgments}

This study was completely sponsored by RIEMSER Arzneimittel AG. We gratefully thank Anja Berensmeier and Gerd Franke for statistical evaluation.

\section{Authors' contributions}

$\mathrm{CM}$ and $\mathrm{LF}$ were responsible for conception and general supervision of the research group. CM, BG, and LF made substantial contributions to data collection and study design. $\mathrm{AB}, \mathrm{GF}, \mathrm{CM}, \mathrm{BG}$, and LF contributed to analysis and interpretation of data; CM, BG, and LF were involved in drafting the manuscript or revising it critically for intellectual content. All authors read and approved the final manuscript.

\section{Disclosures}

Christian Müller and Beatrice Großjohann are employees of RIEMSER Arzneimittel AG. Lutz Fischer declares that he has no competing interests.

\section{References}

1. Charpin D, Birnbaum J, Vervloet D. Epidemiology of hymenoptera allergy. Clin Exp Allergy. 1994;24(11):1010-1015.

2. Barsky HE. Stinging insect allergy. Avoidance, identification, and treatment. Postgrad Med. 1987;82(3):157-158, 161-162.

3. Simone DA, Ngeow JY, Whitehouse J, Becerra-Cabal L, Putterman GJ, LaMotte RH. The magnitude and duration of itch produced by intracutaneous injections of histamine. Somatosens Res. 1987;5(2):81-92.

4. Thomsen JS, Sonne M, Benfeldt E, Jensen SB, Serup J, Menne T. Experimental itch in sodium lauryl sulphate-inflamed and normal skin in humans: a randomized, double-blind, placebo-controlled study of histamine and other inducers of itch. Br J Dermatol. 2002; 146(5):792-800.

5. Golden DB, Marsh DG, Kagey-Sobotka A, et al. Epidemiology of insect venom sensitivity. JAMA. 1989;262(2):240-244.

6. Settipane GA, Boyd GK. Prevalence of bee sting allergy in 4,992 boy scouts. Acta Allergol. 1970;25(4):286-291.

7. Golden DB. Insect sting anaphylaxis. Immunol Allergy Clin North Am. 2007;27(2):261-272, vii.

8. Clark S, Camargo CA Jr. Emergency treatment and prevention of insect-sting anaphylaxis. Curr Opin Allergy Clin Immunol. 2006; 6(4):279-283.

9. Barnard JH. Studies of 400 Hymenoptera sting deaths in the United States. J Allergy Clin Immunol. 1973;52(5):259-264.

10. Tracy JM. Insect allergy. Mt Sinai J Med. 2011;78(5):773-783.

11. Fischer J, Knaudt B, Caroli UM, Biedermann T. Factory packed and expired - about emergency insect sting kits. J Dtsch Dermatol Ges. 2008;6(9):729-733.

12. Schalla W. [Results of a prospective cohort-study.] Pharmazeutische Zeitung. 2009;154(40):3774-3777. German.

13. Weisshaar E, Forster C, Dotzer M, Heyer G. Experimentally induced pruritus and cutaneous reactions with topical antihistamine and local analgesics in atopic eczema. Skin Pharmacol. 1997;10(4):183-190.

14. Karppinen A, Kautiainen H, Petman L, Burri P, Reunala T. Comparison of cetirizine, ebastine and loratadine in the treatment of immediate mosquito-bite allergy. Allergy. 2002;57(6):534-537. 
15. Reunala T, Lappalainen P, Brummer-Korvenkontio H, Coulie P, Palosuo T. Cutaneous reactivity to mosquito bites: effect of cetirizine and development of anti-mosquito antibodies. Clin Exp Allergy. 1991; 21(5):617-622.

16. Tominaga $\mathrm{M}$. The role of TRP channels in thermosensation. In: Liedtke W, Heller S, editors. TRP Ion Channel Function in Sensory Transduction and Cellular Signaling Cascades. Boca Raton, FL: CRC Press; 2007.

17. Steinhoff M, Neisius U, Ikoma A, et al. Proteinase-activated receptor-2 mediates itch: a novel pathway for pruritus in human skin. J Neurosci. 2003;23(15):6176-6180.
18. Moormann C, Artuc M, Pohl E, et al. Functional characterization and expression analysis of the proteinase-activated receptor-2 in human cutaneous mast cells. J Invest Dermatol. 2006;126(4):746-755.

19. Yosipovitch G, Duque MI, Fast K, Dawn AG, Coghill RC. Scratching and noxious heat stimuli inhibit itch in humans: a psychophysical study. Br J Dermatol. Apr 2007;156(4):629-634.

20. Yosipovitch G, Fast K, Bernhard JD. Noxious heat and scratching decrease histamine-induced itch and skin blood flow. J Invest Dermatol. 2005;125(6):1268-1272.

\section{Publish your work in this journal}

Clinical, Cosmetic and Investigational Dermatology is an international, peer-reviewed, open access, online journal that focuses on the latest clinical and experimental research in all aspects of skin disease and cosmetic interventions. All areas of dermatology will be covered; contributions will be welcomed from all clinicians and basic science researchers globally. This journal is indexed on CAS The manuscript management system is completely online and includes a very quick and fair peer-review system, which is all easy to use. Visit http://www.dovepress.com/testimonials.php to read real quotes from published authors.

Submit your manuscript here: http://www.dovepress.com/clinical-cosmetic-and-investigational-dermatology-journal 